\title{
UMA NOVA HISTÓRIA GERAL DIDÁTICA PARA COMPREENDER O MUNDO E AGIR COMO CIDADÃOS GLOBAIS $^{1}$
}

\author{
Ivo Mattozzi $i^{2}$
}

\begin{abstract}
Resumo: No ensaio defendo a necessidade de mudar o modelo de história geral a ser ensinada. Percebemos que a história, como disciplina escolar, corre o risco de se tornar irrelevante. As histórias que estamos vivendo como sujeitos ativos e as que sofremos, exigem um conhecimento muito diferente daquele transmitido tradicionalmente pelos sistemas escolares e uma concepção diferente da história a ser ensinada. O sistema de conhecimento, proposto pelo livro didático, pertence ao gênero historiográfico denominado história geral. O tipo de história geral que foi transposta para os manuais é aquele elaborado a partir do século XVIII e que foi preferido durante o século XIX por historiadores e governantes a outros tipos de história geral, mesmo que tenham sido produzidos ou teorizados. É o tipo de história geral adotada no processo que torna canônica uma narrativa histórica projetada para fundamentar a identidade coletiva da nação por meio de uma narrativa eventográfica. A história geral eventográfica (evenementielle), que fragmenta os processos de transformação e justapõe de forma sequencial os segmentos factuais e cognitivos distribuindo-os espacialmente, mostrou-se completamente inadequada para produzir conhecimentos capazes de explicar a historicidade do mundo atual. Teremos que pensar primeiro nos modelos de história geral a partir dos quais escolher os modelos de origem, aqueles que melhor se prestam a serem transpostos para uma história geral didática. Não encontrei a história geral tratada como objeto de reflexão epistemológica e metodológica em nenhum dos livros mais conhecidos dentre aqueles dedicados ao método histórico. A exceção é a de Johann Gustav Droysen que, na sua Historik, considerou a história geral como o maior produto historiográfico disponível. Geralmente, a história geral tem sido considerada uma produção historiográfica de segunda ordem e modesta em relação às histórias particulares, monográficas e especializadas. Portanto, no artigo, reviso as propostas e realizações de modelos alternativos de história geral e reivindico sua relevância, sua originalidade historiográfica e sua eficácia educacional.
\end{abstract}

Palavras-chave: História geral. História didática. Johan Gustav Droysen.

\section{A NEW GENERAL DIDACTIC HISTORY FOR UNDERSTANDING THE WORLD AND ACTING AS GLOBAL CITIZENS}

\begin{abstract}
In the essay I defend the need to change the general history model to be taught. We realize that history, as a school subject, is in danger of becoming irrelevant. The stories that we are living as active subjects and those that we suffer require a very different knowledge from that traditionally transmitted by school systems and a different conception of the history to be taught. The knowledge system, proposed by the textbook, belongs to the historiographic genre called general history. The type of general history that was transposed into the manuals is that elaborated from the 18th century and that was preferred during the 19th century by historians and rulers to other types of general history, even if they were produced or theorized. It is the type of general history adopted in the process that makes canonical a historical narrative designed to support the nation's collective identity through an eventographic narrative. The general eventographic history (evenementielle), which fragments the processes of
\end{abstract}

\footnotetext{
1 Tradução por Francesco Guerra, Pós-doutorando (bolsista PNPD-CAPES), Faculdade de História, Universidade Federal de Goiás (fguerra@hotmail.it); Loianne Quintela Minduri, Mestre em Comunicação, Faculdade de Educação, Universidade Federal de Uberlândia (loianne.quintela@gmail.com). Revisão e edição técnica Erinaldo Cavalcanti — Professor do Programa de Pós-Graduação em História da Unifesspa.

${ }^{2}$ Professor aposentado pela Universidade de Bolonha (Itálila) e atualmente professor da Faculdade de Educação Universidade Livre de Bolzano-Bozen (UNIBZ).
} 
transformation and sequentially juxtaposes the factual and cognitive segments by spatially distributing them, proved to be completely inadequate to produce knowledge capable of explaining the historicity of the current world. We will have to think first of the general history models from which to choose the original models, those that are better suited to be translated into a general didactic history. I did not find the general history treated as an object of epistemological and methodological reflection in any of the best known books among those dedicated to the historical method. The exception is that of Johann Gustav Droysen who, in his Historik, considered general history as the greatest historiographic product available. General history has generally been considered a second-order historiographical production and modest in relation to particular, monographic and specialized histories. Therefore, in the article, I review the proposals and achievements of alternative models of general history and claim their relevance, their historiographical originality and their educational effectiveness.

Key words: General history. Didactic history. Johan Gustav Droysen.

\section{UNE NOUVELLE HISTOIRE GENERALE SCOLAIRE POUR COMPRENDRE LE PRESENT ET AGIR EN TANT QUE CITOYENS DU MONDE}

Resumé: Dans l'essai, je défends la nécessité de changer le modèle d'histoire générale à enseigner. Nous nous rendons compte que l'histoire, en tant que matière scolaire, risque de ne plus être pertinente. Les histoires que nous vivons en tant que sujets actifs et celles que nous subissons nécessitent un savoir très différent de celui traditionnellement transmis par les systèmes scolaires et une conception différente de l'histoire à enseigner. Il faut alors se demander à quelle histoire attribuer un pouvoir éducatif.. Nous l'appelons l'histoire des manuels, l'histoire de l'école, l'histoire à enseigner et cela nous fait penser qu'il suffit de changer une partie de l'histoire communiquée par les manuels pour répondre à des questions socialement vivantes et lutter contre «les stéréotypes négatifs, vecteurs de malentendus et d'hostilité». Et il semble qu'il suffit de nettoyer l'histoire didactique de ces stéréotypes et de revoir leur idéologie pour avoir une histoire plus appropriée à leur fonction formatrice. Penser l'histoire didactique comme une histoire des manuels nous fait ignorer qu'elle matérialise un genre historiographique. Le système de connaissances, proposé par le manuel, appartient au genre historiographique appelé histoire générale. Le type d'histoire générale qui a été transposé dans les manuels est celui élaboré à partir du XVIIIe siècle et qui a été préféré au XIXe siècle par les historiens et les dirigeants à d'autres types d'histoire générale. C'est le type d'histoire générale adopté dans le processus qui fait du canonique un récit historique conçu pour soutenir l'identité collective de la nation à travers un récit événementielle L'histoire générale evenementielle, qui fragmente les processus de transformation et juxtapose séquentiellement les segments factuels et cognitifs en les distribuant spatialement, s'est avérée totalement insuffisante pour produire des connaissances capables d'expliquer l'historicité du monde actuel. Il faudra d'abord réfléchir aux modèles d'histoire générale parmi lesquels choisir ceux qui sont mieux adaptés pour être traduits en une histoire générale didactique. Je n'ai trouvé l'histoire générale traitée comme un objet de réflexion épistémologique et méthodologique dans aucun des livres les plus connus parmi ceux consacrés à la méthode historique. L'exception est celle de Johann Gustav Droysen qui, dans son Historik, considérait l'histoire générale comme le plus grand produit historiographique disponible. L'histoire générale a généralement été considérée comme une production historiographique de second ordre et modeste par rapport aux histoires particulières, monographiques et spécialisées. C'est pourquoi, dans l'article, je passe en revue les propositions et réalisations de modèles alternatifs d'histoire générale et revendique leur pertinence, leur originalité historiographique et leur efficacité pédagogique. Enfin, nous disposons d'un type d'histoire générale qui nous permet de former la culture historique et la pensée historique nécessaires pour comprendre le présent et agir en tant que citoyens conscients de ce qui se passe.

Mots-clés: Histoire générale. Histoire des manuels. Johan Gustav Droysen. 


\section{UNA NUEVA HISTORIA GENERAL ESCOLAR PARA COMPRENDER EL PRESENTE Y ACTUAR COMO CIUDADANOS DEL MUNDO}

Resumen: En el ensayo defiendo la necesidad de cambiar el modelo de historia general a enseñar. Nos damos cuenta de que la historia, como asignatura escolar, corre el riesgo de volverse irrelevante. Las historias que vivimos como sujetos activos y las que sufrimos requieren de un conocimiento muy diferente al que tradicionalmente transmiten los sistemas escolares y una concepción diferente de la historia a enseñar. Entonces debemos preguntarnos en qué historia queremos apoyar el poder formador. Lo llamamos historia de los libros de texto, historia escolar, historia para enseñar y esto nos hace pensar que basta con cambiar parte de la historia comunicada por los libros de texto para responder preguntas socialmente vivas y luchar contra "estereotipos negativos, vectores de malentendidos y hostilidad". Y parece que basta con limpiar la historia didáctica de estos estereotipos y revisar su ideología para tener una historia más adecuada a su función formativa. Pensar la historia didáctica como una historia de libro de texto nos hace ignorar que materializa un género historiográfico. El sistema de conocimiento propuesto por el libro de texto pertenece al género historiográfico denominado historia general. El tipo de historia general que se traspuso a los manuales es el elaborado a partir del siglo XVIII y que fue preferido durante el siglo XIX por historiadores y gobernantes sobre otros tipos de historia general. Es el tipo de historia general adoptada en el proceso que hace canónica una narrativa histórica diseñada para respaldar la identidad colectiva de la nación a través de una narrativa eventográfica. La historia general eventográfica (evenementielle), que fragmenta los procesos de transformación y yuxtapone secuencialmente los segmentos fáctico y cognitivo distribuyéndolos espacialmente, demostró ser completamente inadecuada para producir un conocimiento capaz de explicar la historicidad del mundo actual. Tendremos que pensar primero en los modelos de historia general entre los que elegir los modelos originales, aquellos que se adaptan mejor a ser traducidos a una historia didáctica general. No encontré la historia general tratada como objeto de reflexión epistemológica y metodológica en ninguno de los libros más conocidos entre los dedicados al método histórico. La excepción es la de Johann Gustav Droysen quien, en su Historik, consideró la historia general como el mayor producto historiográfico disponible. La historia general ha sido considerada en general una producción historiográfica de segundo orden y modesta en relación con historias particulares, monográficas y especializadas. Por ello, en el artículo, reviso las propuestas y logros de modelos alternativos de historia general y reclamo su relevancia, su originalidad historiográfica y su eficacia educativa. Finalmente, tenemos disponible un tipo de historia general que nos permite conformar la cultura histórica y el pensamiento histórico necesarios para comprender y actuar como ciudadanos conscientes de lo que está sucediendo.

Palabras clave: Historia general. Historia do libro de texto. Johan Gustav Droysen.

\section{Introdução - no mundo no qual estamos vivendo precisamos ainda mais da história?}

Refletir sobre essa questão implica que estamos dentro das histórias e as estamos fazendo e que hoje precisamos ainda mais de conhecimento histórico e de método histórico para compreender aquilo que está acontecendo no mundo. Temos à disposição, finalmente, um tipo de história geral e uma consciência metodológica que permitem formar a cultura histórica e o pensamento histórico necessários para compreender e agir como cidadãos conscientes daquilo que está ocorrendo. Escreverei somente sobre a formação da cultura histórica, sem enfrentar o problema da formação das habilidades metodológicas. Porém, temos que ter em conta que os cidadãos precisam também das 
habilidades necessárias para trabalhar com os traços do passado para produzir informações e organizá-las, dando a elas um sentido e comunicando os resultados da reconstrução dos fatos.

Vivemos, ensinamos, agimos como cidadãos dentro de um contexto no qual, hoje mais que nunca, as histórias que acontecem em todo o planeta estão entrelaçadas. A digitalização, que nos traz o mundo e as suas histórias nas rádios, nas tevês, nos smartphones, nos computadores, modifica a percepção do mundo e a quantidade de informações que temos de organizar. As redes sociais impõem novos modos de funcionamento aos regimes democráticos.

As histórias em curso no planeta - junto com o uso público da história representada - invadem as mídias de todos os tipos, os discursos dos políticos e condicionam o nosso cérebro, nossas emoções, nossas imaginações. O passado histórico é representado ficticiamente nos romances, nos filmes, nos quadrinhos, no teatro, nos videogames, nas exposições. A disponibilidade de representações históricas externas à sala de aula e aos manuais modifica a relação entre os cidadãos e a história. As novas mídias nos oferecem a oportunidade de ter acesso a novos conhecimentos históricos a cada dia, ligando a rádio ou a TV ou digitando na internet. Cada um tem a possibilidade de modificar os conhecimentos adquiridos ou de aprender mais história durante a vida. No entanto, isso necessita de elaboração e integração dos conhecimentos novos com os já disponíveis.

A sociabilidade digital produz informações falsas e também aquelas que estão incluídas no que se denomina como pós-verdade, pois se acredita nelas pela força das emoções que produzem. A história representada não é considerada pela grande massa de cidadãos que não percebe estar fazendo história por meio das suas emoções, pelo contrário, acreditando em notícias falsas e em falsas representações do passado e do presente. As ondas do populismo revelam que a história didática não produziu educação histórica, nem prudência nos juízos e nem capacidade de crítica ou de interpretação na maioria dos cidadãos. Os argumentos ilógicos são exprimidos de maneira ampla, sem considerar os fatos e as fontes disponíveis.

As migrações atuais têm ampliado a esfera dos países multiculturais e obrigam a ensinar a superar as ideologias da separação, para evitar os efeitos desastrosos ligados a visões religiosas que conferem uma identidade definida a cada um. Porém, isso implica que o processo de secularização e separação entre poderes políticos e religiosos seja conhecido. 
Os problemas da emancipação feminina, que se verificam segundo níveis diferentes, tanto nos países onde já se afirmou, como naqueles onde as mulheres se encontram ainda numa condição subordinada, requerem o conhecimento do papel desempenhado por elas nas histórias do mundo. Há uma necessidade, portanto, de aprendizado que permita aos cidadãos usar a história para tirar proveito de tanta oferta e aumentar o saber histórico, a compreensão da história e o uso do conhecimento histórico.

Com relação à justiça social, aprendemos às nossas custas, na história que vivemos que nem o conhecimento da história (qualquer que seja), nem as ideologias, por mais inspiradoras e promissoras, são capazes de inspirar ações governamentais que resolvam a desigualdade, senão, talvez, nos países escandinavos.

Provavelmente, os anarquistas, que assassinaram príncipes, estudaram história e tinham a intenção de beneficiar os povos. Eles estavam entre os provocadores responsáveis pelo clima que gerou a Primeira Guerra Mundial. Afinal, os governantes comunistas produziram histórias muito ruins (exceto a contribuição soviética para a derrota da Alemanha nazista). Contudo, aprendemos que a presença dos regimes comunistas mantinha os governantes e os capitalistas nos regimes democráticos e os obrigava a compartilhar melhor a riqueza nacional. Então, o fim dos regimes comunistas produziu a falta de escrúpulos dos gestores do capitalismo financeiro e industrial, que drenam a riqueza mundial em detrimento de outras classes sociais.

Nada garante que o ensino da história (e das ciências sociais e da geografia) produza, em qualquer caso, a formação de uma personalidade "virtuosa e boa", de um sujeito $\kappa \alpha \lambda o ́ \varsigma \kappa \alpha i ~ \alpha \gamma \alpha \theta o ́ \varsigma$, como nós gostaríamos.

Vivemos em um mundo novo, onde as novidades se inserem em características e histórias que foram geradas por processos que ocorreram no passado. No entanto, como sempre, a história em curso é o jardim dos caminhos cruzados, onde podem se abrir perspectivas de transformações positivas, tais como: as ideologias religiosas fundamentalistas poderão ser superadas pela secularização, as injustiças sociais poderão ser mitigadas graças a governos e agentes sociais capazes de tomar decisões que redistribuam a riqueza, a condição feminina poderá melhorar em todas as partes do mundo, a globalização poderá tornar a digitalização do mundo capaz de aumentar a inteligência coletiva.

Portanto, devemos pensar sobre a história e seu potencial formador e educativo para entender como resgatá-la da irrelevância atual. Estamos confiantes de que a 
história como disciplina seja um campo de estudo e de formação de conhecimentos úteis para entender a gênese das características e problemas do mundo atual e nos permitir agir mais conscientemente nas histórias em curso.

Acredito que o estudo da história possa formar tanto mentes mais estruturadas para usar os traços do passado na produção de conhecimentos em cada campo existencial e profissional, como uma capacidade de raciocínio sobre fatos e interpretações dos fatos a fim de construir argumentos mais consistentes, no nível lógico, para explicar os fenômenos.

Porém, há dois problemas que devemos ter em consideração: 1 . A escola não é a única agência de formação das nossas personalidades. Notadamente, as inteligências e atitudes não são uniformes e pode haver personalidades mais ou menos dispostas a aproveitar a lição de Clio. 2. Além disso, esta lição combina-se com a ensinada em outros campos disciplinares e se insere em histórias biográficas sujeitas a mudança nas quais as personalidades dos professores de história influenciam de maneira diferente e em graus variados.

Portanto, não podemos esperar os mesmos benefícios para todos os estudantes e os cidadãos. O estudo da história não tem a capacidade de evitar todos os comportamentos fanáticos, terroristas, antidemocráticos, imbecis e estúpidos de uma parte da população de nossos países e, mais ainda, da população mundial. No entanto, percebemos que a história, como disciplina escolar, corre o risco de se tornar irrelevante. Por esse ângulo de percepção, só podemos salvá-la mudando a história que queremos ensinar.

As histórias que estamos vivendo como sujeitos ativos e as que sofremos exigem um conhecimento muito diferente daquele transmitido tradicionalmente pelos sistemas escolares e uma concepção diferente da história a ser ensinada. Devemos, então, nos perguntar de qual história estamos falando e em qual história queremos apoiar o poder formador.

Que tipo de formação se impõe para o cidadão competente num mundo em que abundam as fake news e a post-truth, as investigações judiciais televisionadas e a necessidade existencial de construir conhecimentos mediante o uso de traços empregados como ferramentas para produzir informações em qualquer campo profissional e disciplinar? É necessário promover uma formação ao cidadão através de um treinamento histórico no qual o método histórico no exercício do uso dos traços do passado e na construção do conhecimento seja intensamente proposto aos alunos. Em 
resumo, vários acontecimentos no mundo atual demandam uma formação que a história pode ajudar a promover com recursos peculiares. E hoje os recursos que a história nos disponibiliza são mais eficazes do que no passado.

\section{De qual história precisamos?}

Quando eu disse história, imagino que cada um de vocês tenha pensado em um campo disciplinar específico, nos conhecimentos produzidos nesse campo e na história ensinada que deriva disso.

Parece que esta palavra "história" designa facilmente o mesmo objeto em todos os tempos e para todos os usos. Até os historiadores pensam que existe uma e apenas uma história para ensinar e fazer aprender, e afirmam com confiança que "basta conhecer a história” para poder ensiná-la bem. Eles não percebem que não há uma única história e que o que eles têm em mente é uma história que inibe a inteligência do mundo ${ }^{3}$. Esta é uma ilusão falaciosa e nós, professores e os alunos aos quais ensinamos, devemos nos libertar dela.

Falamos de história como se houvesse um objeto único, válido em qualquer caso, disponível para a educação em qualquer caso. Falamos de história como se a disciplina incluída nos currículos escolares fosse uniforme em todos os países. Contudo, sabemos que a história ensinada nas escolas nem sempre foi a mesma e não é a mesma atualmente.

Em geral, para a maioria dos cidadãos que conheceram a história na forma exposta na escola, a palavra designa e evoca a representação do passado oferecido pelos livros escolares. Eles não conseguem pensar no campo disciplinar dos historiadores. Não é a história dos historiadores que molda o conhecimento histórico dos cidadãos, mas é a história proposta nas salas de aula. Entretanto, nem mesmo a história dos historiadores é a verdade indiscutível. No campo disciplinar existiram e existem histórias manipuladas e o conhecimento, oferecido nas salas de aula de escolas e universidades, pode ser o resultado de muitas omissões históricas conforme defendem Denis Mack Smith (2002) e Jack Goody (2008).

Portanto, temos que fazer uma escolha no campo historiográfico, identificando com um adjetivo a "história" a ser ensinada, aquela que deve ser valorizada como capaz

\footnotetext{
3 MAtrozzI, Ivo. Basta sapere la storia per insegnare bene?, Storia \& Futuro, 23, giugno 2010, www.storiaefuturo.com (Acesso: 01/03/2017), primeiro e-book, o qual é focado em um tema que nos é particularmente caro: "La formazione degli insegnanti di Storia: bilancio delle SSIS e prospettive", Anais do congresso realizado em Bologna em 17 de outubro de 2008.
} 
de formar o pensamento histórico e o espírito crítico, e destacada com relação às historiografias que revelaram a fraqueza da sua estrutura teórica tanto no nível cognitivo quanto no educacional. A historiografia eventográfica (evenementielle), que fragmenta os processos de transformação e justapõe de forma sequencial os segmentos factuais e cognitivos distribuindo-os espacialmente, mostrou-se completamente inadequada para produzir conhecimentos capazes de explicar a historicidade do mundo atual. A segmentação e a justaposição impedem que se verifique aquele sistema que assegura que o conhecimento geral seja superior à soma das partes.

No campo da história didática, chamamos essa disciplina com a mesma palavra, seja quando era trivial e pretendia treinar súditos devotos e agressivos contra outras nações, com representações falsas e banais, seja agora que está tentando oferecer um conhecimento mais adequado à necessidade de entender o mundo. E parece que ela cumpriu sua função formativa quando preparou para as guerras e agora que esperamos que forme cidadãos ativos e democráticos. Novamente, precisamos ser claros: por muito tempo nas escolas não foi ensinada a história, mas sim uma falsificação dela. Como se considerássemos que a alquimia fosse a química ou os mitos que contam as origens do mundo com imaginação fossem a história. A história dos livros didáticos poderia ter sido mais agradável quando oferecia narrativas sobre personagens e eventos exemplares, capazes de inspirar modelos de heroísmo ou bom comportamento, digno dos súditos. Porém, era uma história estúpida.

A chamamos de história de manual, história escolar, história para ensinar e esta nos faz pensar que basta mudar parte da história comunicada pelos livros didáticos para responder a perguntas socialmente vivas e lutar contra "estereótipos negativos, vetores de mal-entendidos e hostilidade". E parece que é suficiente limpar a história didática desses estereótipos e revisar sua ideologia para ter uma história mais apropriada à sua função formadora ${ }^{4}$.

\footnotetext{
4 "Uma rápida e recorrente análise da história escolar coloca em evidência a preocupação em combater estereótipos negativos, portadores de mal-entendidos e de hostilidade e, portanto, em corrigir discursos históricos escolares e, em particular, os manuais/livros didáticos. Essa foi uma das primeiras missões do Instituto Georg Eckert depois da Segunda Guerra Mundial, que trabalhou pela reconciliação francoalemã, garantindo o retrato equilibrado de cada povo nos manuais do outro país. Ainda é recente a revisão dos manuais sérvios, croatas e bósnios (escritos para a comunidade muçulmana) na Bósnia ou o debate sobre o tratamento da ocupação japonesa na Ásia nos manuais japoneses". TUTIAUX-GUILLON, Nicole. (organizado), L'histoire scolaire au risque des sociétés en mutation. Introduction au dossier, L'histoire scolaire au risque des sociétés en mutation, dossiê da revista Raisons, comparaisons éducations. La revue française de l'éducation comparée, n. 4, janvier 2009, p. 11-17, citação na p. 12.
} 
Em outros casos, a história dos manuais se opõe, geralmente, à história dos historiadores que produz conhecimentos especializados e monográficos. Em suma, parece-me que não esteja na agenda a necessidade de substituir o indecente sistema de conhecimento histórico do século XIX por outro. Pensar na história didática como uma história de manual nos faz ignorar que ela pertença ao gênero historiográfico. O sistema de conhecimentos, proposto pelo livro didático, cria o gênero historiográfico da história geral. O tipo de história geral que foi transposta para os manuais é aquele elaborado a partir do século XVIII e que foi preferido durante o século XIX por historiadores e governantes a outros tipos de história geral, mesmo que tenham sido produzidos ou teorizados.

É o tipo de história geral adotada no processo que torna canônica uma narrativa histórica destinada a fundar a identidade coletiva da nação ${ }^{5}$. A história dos manuais não se opõe à história dos historiadores, pois eles também são produtores de histórias gerais, bem como de trabalhos monográficos. Teremos que pensar primeiro nos modelos de história geral a partir dos quais escolher os modelos de origem, aqueles que melhor se prestam a serem transpostos para uma história didática geral.

\section{A história geral na origem da história escolar canônica: uma história de pouco valor?}

Não encontrei a história geral tratada como objeto de reflexão epistemológica e metodológica em nenhum dos livros mais conhecidos dentre aqueles dedicados ao método histórico. A exceção é a de Johann Gustav Droysen que, na sua Historik, considerou a história geral como o maior produto historiográfico disponível. Geralmente, a história geral tem sido considerada uma produção historiográfica de segunda ordem e modesta em relação às histórias particulares, monográficas e especializadas.

Ainda em 1999, um prestigiado historiador italiano, Marino Berengo, sentiu a necessidade de escrever uma nota preliminar para justificar ter se dedicado à escritura de sua grande obra sobre a civilização urbana europeia entre os séculos XIII e XVII. Ele alertou que os autores de obras especializadas teriam considerado a sua como uma

\footnotetext{
5 "Esse trabalho questiona a constituição e a transmissão da história pela escola e pelos museus, em um contexto de globalização. Relaciona-se mais especificamente ao processo de 'canonização 'de uma narrativa histórica que contribuiria para a identidade coletiva. [...] Treze capítulos estão agrupados em três partes: o enquadramento do conhecimento histórico, fundamentos e revisões do cânone ocidental, transmissão do conhecimento histórico em contextos multiculturais". Resenha de TUTIAUX-GUILLON, Nicole. em L 'histoire scolaire au risque des sociétés en mutation, p. 185-188.
} 
“compilação" que não beneficia a reputação do historiador profissional ${ }^{6}$. Ora, compilar significa escrever, compor, editar obras que não exigem originalidade porque são produzidas pela coleta e coordenação de materiais retirados de outras obras.

Portanto, se considerarmos todas as obras de história geral como compilações, elas serão desqualificadas por falta de originalidade, cultura e erudição. A mesma preocupação foi expressa em 1919, por Émile Gautier, que, em vez de "compilação", usou a palavra "síntese": "Para arriscar-se à síntese histórica, não se deve ter nenhuma reputação de historiador a perder" (DEMANDT, 2004, p. IX).

De fato, as obras de história geral amplamente presentes nas casas dos homens cultos e nas escolas eram compilações. Limitavam-se a sintetizar, eliminando grandes quantidades de detalhes, os conhecimentos sobre fatos heterogêneos da história política e institucional e os eventos bélicos, e os reuniam, sem estruturá-los, em conhecimentos novos. A partir disso derivaram os livros de "história" que circulavam nas escolas, as compilações mais exageradas que impunham a imagem da história ao público culto. E, ao longo do século XX, a história geral representou o gênero historiográfico do qual a história escolar procede. O tipo de história geral tido como normativo e formativo adotado pelos governos é aquele que resume os eventos político-institucionais que reconstroem a formação das nações e as guerras entre os Estados ${ }^{7}$. Como ressaltou Nicole Tutiaux-Guillon (2009):

\footnotetext{
6 "As oportunidades acadêmicas — que ao fim de uma longa carreira não tem dificuldade em confessar ter respeitado na juventude - e depois as exigências didáticas concretas me mantiveram, naquele tempo, longe da história comunal e senhorial (medieval), cuja fascinação, no entanto, sempre me acompanhou de perto. Para alimentá-la, criou-se em mim um certo sentimento de insatisfação diante da intensificação na produção histórica italiana de uma especialização cada vez mais acentuada, tanto temática quanto cronológica. $\mathrm{O}$ descrédito que acomete e envolve o conceito de compilação constitui, num nível geral, o reflexo e, ao mesmo tempo, a raiz dessa insatisfação. O Grande Dicionário Utet da língua italiana nos oferece, sobre esse descrédito, a perspectiva correta: 'muitas vezes há uma nuance depreciativa ligada a ele, indicando a ausência não apenas de novidade, mas também de doutrina e erudição autênticas'. Juntar as coisas está, portanto, tornando-se uma atividade que não é prudente praticar. E, embora não seja objeto da tal proclamada falta de estima, outro tipo de trabalho, mais específico, mas não totalmente relacionado ao anterior, corre o risco de cair em desuso: o da história comparada. Para conectar um certo processo que temos observado em um determinado lugar — talvez em uma cidade — com o que acontece em outros lugares, é necessário olhar em várias direções, mas, como é impossível realizar pesquisas diretas em qualquer lugar, é preciso recorrer àquelas de segunda mão; antes de tirar as conclusões, é preciso portanto compilar". MARINO BERENGO, L'Europa delle città, Torino: Einaudi, 1999, p. XII-XIII.

${ }^{7} \mathrm{O}$ ensaio de Pilar Maestro Gonzalez, "El modelo de las historias generales y la enseñanza de la historia; limites y alternativas" (em: Usos publicos de la historia, Ponencias del VI Congreso de la Association de Historia Contemporanea (Universidad de Zaragoza, 2002), Prensa Universitaria de Zaragoza, Zaragoza 2003), é importante para se entender como as histórias gerais nacionais estão na origem dos livros escolares. A partir desse ensaio, descobrimos que duas histórias gerais do século XIX foram os modelos adotados pelas pessoas de cultura, para pensar a representação da história, e pelos governantes espanhóis, para estabelecer o currículo do conhecimento histórico. As duas obras foram: PADRE MARIANA, Historia general de España, la compuesta, enmendada y añadida por el Padre Mariana, con la continuación de Miniana [...], Madrid, 1855 e Modesto LAFUENTE, Historia General de España desde los tiempos
} 
Na maioria dos países, pelo menos desde o século XIX, a história didática pretendia construir a coesão nacional compartilhando as mesmas memórias (guerras contra o inimigo, grandes ancestrais, progressos políticos e sociais) por meio de um discurso sobre as origens, da narrativa do advento do presente e por uma iconografia onde as figuras do povo e dos heróis tinham o mesmo lugar. Esses princípios presidiram a escolha do conteúdo em programas oficiais e a redação de manuais, seja nos casos em que havia somente um oficial, seja que fossem colocados em competição. Nessa ocasião, essa história do Estado-nação foi enriquecida ajustando-a ou complementando-a com a história da Europa ou do mundo. Essa história durou até o final de 1960. (TUTIAUX-GUILLON, 2009, p. 11).

Contudo, continuou sendo o eixo narrativo mesmo depois de 1960 até hoje, na mente dos autores e editores da maioria dos livros didáticos do ensino médio, aqueles que deveriam formar historicamente todos os cidadãos. Claro, existem novidades nos manuais, como Rafael Valls (1997) indicou em uma fórmula sintética:

A historiografia mais recente colocou basicamente duas grandes questões. Em primeiro lugar, o aprofundamento da tematização, ou seja, a abertura para novos temas e novos grupos sociais que antes não possuíam voz própria. Assim, diversos aspectos fundamentais se tornaram parte da historiografia, como a construção daqueles que conheceram ou foram capazes de obter "um lugar na história". (VALLS, 2007, p. 129).

Poderíamos nos contentar com uma integração secundária, à margem do eixo narrativo que continua a privilegiar os fatos político-institucionais e ordená-los na sucessão cronológica que os segmenta em eventos? Concordo com a análise e as preocupações expressas com clareza por Luis Alberto Romero (2004):

A tendência à abertura e dispersão enraizou-se nos manuais que surgiram nos últimos anos [...]. Enquanto a narração contínua, fechada e autoritária era criticada, o projeto gráfico reduzia o espaço do texto principal e enchia as páginas de elementos complementares e que distraíam os leitores. Através desses elementos, outras vozes se incorporavam à narração principal, mas com tanta força que o eixo narrativo, reduzido à sua expressão mínima, se perdia no conjunto dessa história. (ROMERO, 2004, p. 221).

Atualmente, apenas a alternativa da história em escala mundial da World History ou Global History parece se opor ao modelo canônico tradicional. Mas essa alternativa não pode satisfazer todas as necessidades da formação histórica dos cidadãos que precisam conhecer também a história geral de seu continente e de seu estado e região. A história em escala mundial deve ser considerada um tipo de história geral e parte dela.

primitivos hasta la muerte de Fernando VII, Continuada desde dicha época hasta nuestros dias (muerte de Alfonso XII) por D. JUAN VALERA con la colaboración de D. ANDRÉS BorREgo y D. ANTONIO PIRALA. Impresa en Barcelona por Montaner y Simón entre 1888 y 1890. 


\section{Em busca de uma história geral alternativa}

Proponho considerar a história geral como um gênero historiográfico que merece ser objeto de reflexão epistemológica e metodológica e que possa produzir conhecimentos originais, inalcançáveis para a historiografia especializada e monográfica. Uma produção historiográfica capaz de produzir conhecimento que possa suprir melhor a sede de conhecimento sobre o mundo histórico, melhor promover a compreensão do mundo atual, instigar o pensamento histórico e o espírito crítico.

A historiografia nos fornece muitos tipos de história geral que podem ser transpostos para a história didática geral mais adequada às necessidades da formação dos cidadãos na era da globalização. Já durante o século XIX, ao lado do modelo político-institucional, eventográfico (evenementielle), cronológico-linear, foram propostos tipos de histórias gerais fortemente alternativos àqueles que se tornaram canônicos na editoração científica e nas escolas.

Um exemplo muito importante foi dado em 1828 por François Guizot, que propôs uma história da civilização europeia aos estudantes que frequentavam seu curso de história moderna na Sorbonne:

Eu pensei que um quadro geral da história moderna da Europa, considerada como um desenvolvimento da civilização, uma visão geral da história da civilização europeia, de suas origens, seu desenvolvimento, seu escopo, seu caráter; pensei que tal quadro pudesse ser adequado para o tempo de que dispomos. (GUIZOT, 1956, p. 11).

Suas lições e o livro que as reúne são um modelo de como tematizar e como ensinar história geral. Guizot não pretende expor genericamente a história da Europa, concatenando os eventos político-institucionais. Ele identifica e delimita um tema: a formação da civilização na Europa Ocidental desde o final do Império Romano do Ocidente até o início do século XIX. De tal modo, assume um princípio que lhe permite selecionar e estruturar os fatos a serem levados em consideração no oceano dos fatos possíveis. A escolha possibilita dar organicidade e consistência ao conhecimento histórico. O tema enfoca um processo de transformação que pode satisfazer aqueles que se perguntam: "como se formou em treze séculos a civilização europeia a partir do estágio em que a civilização romana estava no quinto século?”.

O segundo passo consiste em compartilhar a conceitualização do objeto da representação historiográfica e reconhecer a civilização como um fato, ou melhor, como “o fato por excelência, o fato geral e definitivo, ao qual todos os outros se referem e no 
qual eles se resumem" (GUIZOT, 1956, p. 11). O terceiro passo consiste em antecipar a maneira de tratá-lo, o quarto em relacioná-lo com o presente e recuperar os conhecimentos já possuídos pelos alunos.

Em resumo, as lições de Guizot nos oferecem também um modelo de história geral através da seleção do objeto a ser tematizado e com o modo de tratá-lo na comunicação didática. Portanto, é necessário reconhecer as características da civilização moderna e identificar as séries dos elementos que a compõem para poder reconstruir suas histórias. Com essa finalidade, Guizot convida a pensar nas muitas características da civilização europeia do início do século XIX e a compará-la com as civilizações antigas, que eram muito mais uniformes e dominadas por um único elemento ${ }^{8}$. Depois de Guizot, surgiu Droysen, o inventor da civilização helenística, que, em suas aulas universitárias, teorizou a história geral. Droysen é um dos poucos historiadores que defenderam a superioridade da história geral contra as histórias especializadas. Ele as distingue claramente e até faz coincidir a história com a história geral, enquanto chama de "histórias" aquelas dos especialistas.

[...] Nessa distinção entre a história geral e a história especializada está a possibilidade de sair da extrema confusão sobre o que a história deve conter. [...] Posso querer investigar a história de minha família, que interessará a poucas pessoas além de mim, mas essa é, por si só, igualmente de natureza histórica e deve ser tratada com o mesmo método histórico que o da casa de Habsburgo ou Howard. Quem negaria que até a vila de Vaduz ou o pequeno Estado de San Marino tenham suas histórias? Todavia, elas não interessariam tanto aos demais quanto aos diretamente envolvidos. Isso quer dizer que essas histórias não têm nenhum interesse geral ou superior. Passamos agora a determinar qual é a natureza desse interesse maior e geral (ou, de acordo com a expressão que usaremos, o que distingue a história das histórias) (DROYSEN, 2003, p. 497498).

Portanto, entre os produtos da historiografia — segundo Droysen —, as obras dos historiadores especializadas e monográficas formam o universo das histórias, enquanto apenas à história geral é legítimo aplicar o nome "história", pois fornece a visão geral das comunidades e das forças que agem no mundo histórico. Nesse sentido

\footnotetext{
${ }^{8}$ Guizot foi um historiador estimado por Droysen, que escreveu sobre ele em dois pontos: "em nosso presente há a mesma ignorância da massa, a confusão daqueles que ainda estão se formando ao lado do profundo conhecimento de um [Guizot], um Ranke ou um Dahlmann”, p. 387. No entanto, em relação à história da civilização europeia de Guizot, expressou algumas reservas, apesar de avaliá-la positivamente: "Eu certamente poderia mencionar o curso das aulas de Guizot [...] nas quais há uma concepção elevada da história da civilização, substancialmente conforme com o que emergiu das nossas reflexões. Todavia Guizot prefere a maneira, um tanto extravagante, de uma esquematização doutrinária dos motivos emergentes e, portanto, trabalha demasiadas vezes com abstrações falsas. No entanto, sua obra está entre as mais interessantes", p. 520. Droysen faz a citação com respeito a outros historiadores que foram autores de histórias gerais.
} 
ele destaca que "pelo menos em teoria começa-se a reconhecer que a história deve incluir também as formações sociais e jurídicas, intelectuais e estéticas, religiosas e técnicas da humanidade que se condicionam e se explicam mutuamente" (DROYSEN, 2003, p. 91).

Uma pequena antologia de citações da Historik de Droysen é suficiente para entender como ele pode ser considerado o inspirador de histórias gerais que podem ser transpostas para uma história escolar perspicaz. O que ele escreveu sobre a função formadora da história é precisamente o que recomendamos hoje para o ensino da história: para ele, "os estudos históricos têm por objetivo a tarefa de estimular a se pensar historicamente. [...] Pensar historicamente não é de modo algum, prerrogativa do pesquisador ou do estudioso de historiografia [...]" (DROYSEN, 2003, p. 81).

E para dar força às suas declarações, ele prossegue refletindo sobre a história efetiva, isto é, a real. Deveríamos fazer com que os estudantes e todos os cidadãos pensem que cada um de nós é o produto de uma história e está vivendo uma história. Nas palavras de Droysen:

Cada um de nós, individualmente, é, em um certo sentido, o resultado de uma história, é determinado, por meio da educação, da formação intelectual, do hábito, do preconceito, por uma riqueza infinita de representações cuja interpenetração inconsciente e síntese constituem a plenitude espiritual do nosso eu, a unidade do nosso querer e poder. (DROYSEN, 2003, p. 85).

Mais ainda, o mundo atual deve ser pensado como o resultado de processos de transformação que ocorreram no passado. E o passado está presente sob a forma do resultado de tais processos e dos traços do passado. Nesse sentido ele reforça que

[...] tal como a realização desse eu, igualmente, todo o rico conteúdo de nosso povo e de nossa época são, como bem sabido por cada um, um resultado histórico, e somente e antes de tudo enquanto seu resultado; o passado não passou; ele existe idealmente nesse resultado. [De modo análogo existiriam todas as épocas, todos os povos, todos os presentes que nos precederam]. Essas épocas [defende Droysen] efetivamente se passaram, exceto na medida em que ainda estão presentes como resultado ou como resíduo (DROYSEN, 2003, p. 85-86).

Droysen segue enfático com essa reflexão e sentencia que "de fato cada ponto no presente, cada coisa e cada pessoa é um resultado histórico, contém em si uma infinidade de relações que, neste presente, foram enterradas e interiorizadas" (DROYSEN, 2003, p. 88). O autor vê, com clareza, que é necessário apreender os aspectos que tornam mais transparente a relação do presente com os processos 
históricos que os geraram: "no presente percebemos distintamente como em cada situação o novo emerge aqui ou acolá" (DROYSEN, 2003, p. 522).

Entretanto, aquele chama a atenção para o fato de que:

[...] o movimento do presente e a necessidade de compreendê-lo e inscrevê-lo na grande continuidade da história induzem irresistivelmente a sentir, se assim posso dizer, o pulso da história nesses pontos salientes. E nenhum movimento histórico será compreendido fora desses pontos salientes. (DROYSEN, 2003p. 523).

Não seria uma boa estratégia pedagógica/educacional ensinar os alunos a sentirem o pulso do presente para perceberem os pontos salientes nos quais se convergem os processos históricos? E não seria enriquecedor, do ponto de vista educativo, revelar os fatos históricos dos quais são artífices homens e mulheres sem poder? Droysen os caracteriza para seus alunos como "trabalhadores" e "mestres de obra" da história:

Está claro então que o homem pode ser o criador da história de duas maneiras; pode sê-lo, de fato, sem saber, mesmo aquele que simplesmente se dedica a seus negócios, aquele que faz comércio, um métier, quem se dedica a uma arte, uma ciência e assim por diante. Movendo-se na esfera das potências éticas, mediatamente ele produz também algo histórico - mas o que ele faz não tem valor para ele, que considera apenas como um acontecimento pessoal. [...] De fato, deve-se dizer que a maioria dos movimentos históricos, e frequentemente os mais significativos, são realizados dessa maneira. Objetivos limitados estão em ação, as paixões comuns dos homens - geralmente as mais baixas: ganância, vaidade, fanatismo, desejo de dominação. Essa é a engrenagem que, em certo sentido, o pensamento histórico usa para começar a trabalhar [...] (DROYSEN, 2003, p. 527).

\section{E continua:}

Diante desses trabalhadores da história - poderíamos chamá-los de operários e carpinteiros - estão os mestres de obra. Quero dizer, aqueles que, também na atividade cotidiana, sabem do que se trata, ou seja, sabem que não é apenas um trabalho diário ou um negócio efêmero, mas que todo trabalho, toda ação, até a menor delas, é um elo na grande corrente da história. [...] Conscientes da grande conexão dos eventos históricos, eles reconhecerão o passado na sua própria direção e, com uma adivinhação criativa, perceberão e prefigurarão o futuro. Eles se inserirão consciente e intencionalmente na dialética dos pensamentos históricos e, através deles, essa dialética terá seu cumprimento. (DROYSEN, 2003, p. 528).

E depois de ter considerado que são os trabalhadores e os mestres de obra que mobilizam os processos históricos mais relevantes, os que produzem o devir da humanidade, Droysen retorna à historiografia e reafirma que a "história", isto é, a 
história geral, deve lidar com as histórias reais que são relevantes para o movimento progressivo da humanidade:

Em um outro contexto, deixamos claro que a história é diferente das histórias e definimos o seu objeto. Na história, lidamos com o que reconhecemos eficaz para o movimento progressivo da humanidade. A história do passado, dissemos, é um olhar retrospectivo a partir do presente. Porém, toda a vasta sucessão que idealmente construímos é uma série interminável de presentes que já foram. (DROYSEN, 2003, p. 530).

Droysen, portanto, propôs uma história geral radicalmente diferente daquela que havia se estabelecido na cultura e no ensino. Seu modelo era distinto em razão das hierarquias de relevância dos fatos históricos e dos sujeitos responsáveis por seu desempenho, das formas de estabelecer os nexos entre passado e presente, das funções cognitivas e intelectivas atribuídas ao conhecimento do passado, realizado segundo um método histórico rigorosamente crítico.

\section{A história geral nos séculos XX e XXI}

Depois de Droysen, encontramos, no limiar do século XX, uma exaltação da história geral, na França, na Revue de Synthèse Historique. O fundador, Henri Berr (1981), a reivindica programaticamente como uma necessidade. Ele prefere denominála com o termo mais operacional de síntese, mas as palavras-chave também são "quadro de generalidade" e "geral".

Como Droysen, Berr também contrapõe os trabalhos especializados à síntese, mas, do mesmo modo, realiza o diagnóstico e atribui a desvalorização da história geral à miopia dos especialistas que se apaixonam apenas por pesquisas "fragmentárias":

Seus adversários inconciliáveis serão, por outro lado, apenas aqueles que se sentem alarmados ou obscurecidos pela mera palavra 'síntese'. Existem talentos de valor inegável, que concebem o trabalho científico apenas na forma de pesquisas fragmentadas e que, devido à infinidade do detalhe, avançam na pesquisa apenas para ver sua conclusão se afastar. Eles têm pena dos imprudentes que desejam ir além do horizonte limitado do que estudaram pessoalmente e que visam formar um quadro geral, mesmo que seja em um setor ainda restrito. (BERR, 1981, p. 48).

Em seguida, Berr deixa claro, a seu modo, a relação entre as "histórias" e a "história", como Droysen teria dito, e o ciclo de produção que as conecta e produz a renovação cíclica das histórias gerais: 
Existe um primeiro nível nos estudos históricos, o da pura erudição, no qual os fatos são submetidos a uma avaliação crítica. Os fatos apurados, matéria-prima da história, podem ser posteriormente elaborados de duas maneiras, dependendo de seu agrupamento em relação a unidades determinadas - grandes homens, povos, instituições - em série, por assim dizer, individuais ou que se confrontam para se saber o que é análogo em toda parte na história, para descobrir o geral na sucessão dos eventos particulares, na diversidade de indivíduos e povos. (BERR, 1981, p. 47).

Com outros argumentos, Berr também exalta a superioridade cognitiva da história geral e, ironicamente, opõe a elaboração da síntese ao colecionismo dos fatos. Para ele:

Os ciclos de síntese têm a vantagem de despertar a consciência do pesquisador em relação à sua própria tarefa. Se a ciência não fosse nada mais que a satisfação de uma curiosidade, nada mais que jornalismo retrospectivo, seria realmente inútil. A confusão dos fatos é nula. Não existe ciência, de acordo com a fórmula antiga, que não seja ciência do geral. [...] O colecionador de fatos certamente não é mais apreciável do que o de selos ou conchas. A síntese é útil, mesmo no nível moral, porque permite entender a dignidade da ciência. [...] O que pretendemos fazer aqui é ciência, ciência verdadeira, ciência total. Ninguém entrará aqui, poderíamos dizer, se não possuir o bom método. (BERR, 1981, p. 48).

Por fim, Berr também atribui à operação de construção das sínteses a função de ser útil tanto para especialistas quanto para toda a humanidade. De fato, ele conclui a apresentação do programa do laboratório da revista com estas palavras confiantes: "No âmbito das ciências humanas, há um trabalho importante e urgente a ser realizado que, além dos homens de ciência, deve ser útil a toda a humanidade”. (BERR, 1981, p. 49).

Contudo, nas páginas anteriores, ele já havia exaltado o propósito do conhecimento da história geral em benefício da comunidade política:

Do conjunto desses estudos, da construção dessa psicologia histórica, depende não apenas a compreensão do passado, mas o controle do futuro. Afirma-se, com razão, que o biólogo negligencia as características específicas de cada organismo. O mesmo não pôde ser dito do médico. Ele precisa do conhecimento do geral, bem como do particular, ou melhor, do individual. E o mesmo acontece com o homem, o político ideal: e o político ideal é o historiador perfeito. (BERR, 1981, p. 47).

Não me parece que Droysen e Berr tenham considerado a história geral tradicional como uma criação digna de atenção ou que pudesse ter as características da história geral que eles desejavam. Como se nenhuma outra forma de história geral existisse, Berr toma a iniciativa de promover a elaboração de novas histórias gerais coerentes com os critérios que ele definiu. 
Em 1920, ele funda a série L'évolution de l'Humanité e escreve o prefácio de vários volumes. O catálogo dos cem volumes programados oferece obras de história geral que permitem conhecer as civilizações e processos que transformaram a história do planeta e da humanidade. Cada obra é concebida como um elemento do todo, do sistema de conhecimentos que deve tornar os presentes passados e o devir do mundo conhecidos.

Berr também teve o mérito de estimular Lucien Febvre e Marc Bloch a escrever obras de história geral e de torná-los defensores de uma nova história geral. Acredito que não foi reconhecida como uma característica da atividade dos historiadores que constituíram os Annales a atenção e interesse compartilhados pelas histórias gerais e a capacidade de tais historiadores de pensá-las de maneira distinta da história tradicional. De fato, Pirenne, Febvre, Bloch e Braudel foram autores de histórias gerais e críticos exigentes de histórias gerais escritas por outros.

Indícios do interesse de Febvre pela produção de história geral ainda são revelados por seus projetos de escrever livros sobre a história da Europa. Em 1925, ele inseriu dois títulos sobre o assunto na série de Henri Berr: A Europa e o espírito europeu no século XVI; A Europa e o universo no final do século XVIII. Ele escreveu cerca de trinta resenhas de obras sobre a Europa moderna e contemporânea e, na resenha do trabalho de Pirenne sobre as cidades europeias na Idade Média, exaltou o trabalho como uma história geral, uma síntese magistral, uma visão geral sobre um aspecto da civilização medieval ${ }^{9}$. Em 1944-45, Febvre desenvolveu um curso sobre civilização europeia no Collège de France, e ele o apresentou como "um esquema de uma investigação geral" (FEBVRE 1999, p. 114).

A conotação de "história geral" se tornou para Febvre uma marca de superioridade, não um estigma que comprometia a reputação do autor. $\mathrm{O}$ valor dado à história geral levou-o a projetar a série Historia Mundi pela editora Armand Colin e a começar a colaborar com a UNESCO em projetos de história mundial, após sua intervenção na primeira assembleia da UNESCO na qual pediu a substituição da palavra "civilização" no singular para o plural, pois todas as civilizações formam a

\footnotetext{
${ }^{9}$ Les villes du moyen àge, essai d'histoire économique et sociale. Com menos reservas, diria com prazer: ensaio sobre história geral. [...] A síntese magistral que ele propôs e realizou é de um outro porte, também de uma outra envergadura. É uma visão geral de alguns aspectos fundamentais da civilização medieval que, com um poder incomparável, feito de bom senso, de razão lúcida, de imaginação também e de inteligência histórica singularmente refinada, um mestre historiador extraiu para nós o tesouro de sua documentação e de sua experiência". Cf. FEBVRE, 1965, p. 412.
} 
humanidade $^{10}$. Em 1953, Febvre tornou-se editor da revista mundial da UNESCO, Cahiers d'Histoire Mondiale, e na primeira edição escreveu uma premissa na qual zombava da história geral centrada em eventos militares:

"L'Histoire, c'est la guerre": des gens à courte vue ne cessent encore de le proclamer, aux applaudissements des badauds. Et ils ont raison sans doute si l'Histoire doit se résumer en une suite d'intrigues et d'habiletés criminelles, d'aggressions et de fureurs dévastatrices, de cyniques entreprises de pillage... ${ }^{11}$ (FEBVRE, 1953, p. 198).

E, em um ensaio de 1959, Braudel lembrou a apreciação de Febvre pela história geral com estas palavras:

Contra Léon Brunschwig e Étienne Gilson, contra uma história autônoma das ideias, Lucien Febvre reivindicou com razão os direitos da história geral, atenta à complexidade da vida, da qual nada pode ser dissociado, se não arbitrariamente. Porém, reconstituir sua unidade significa buscar infinitamente tornar o círculo quadrado. No entanto, é impossível hesitar quando se trata da história da civilização, pesquisada não mais em um dos seus âmbitos particulares, mas como um todo: não está claro, então, como ela poderia se dissociar da história geral ou, como se diz, da história global. (BRAUDEL, 1959, p. 220).

Por seu lado, Bloch considerou uma obra de história geral como a Histoire de Belgique de Pirenne um "dos mais indispensáveis nutrimentos intelectuais para qualquer cultura histórica digna desse nome" (BLOCH, 1997, p. 273) $)^{12}$. E dedicou várias resenhas a obras de história geral publicadas no entreguerras ${ }^{13}$. E o que Braudel

\footnotetext{
${ }^{10}$ Febvre dedicou um texto importante à evolução do conceito de civilização. "Civilisation: évolution d'un mot et d'un group d'idée" como um prefácio ao volume "Civilisation, le mot, l'idée, Première Semaine Internationale de Synthèse", Paris 1930. FEBVRE, 1966.

11 "História é guerra": os míopes continuam a proclamá-la, sob o aplauso dos espectadores. E têm razão, sem dúvida, se a História se resume numa série de intrigas e habilidades criminais, agressão e fúria devastadora, empreendimentos cínicos de pilhagem. (Tradução livre).

${ }^{12}$ BLOCH, Marc, Henri Pirenne, storico del Belgio, BLOCH, Marc. Storici e storia, Torino: Einaudi, 1997, p. 273-277: "O primeiro volume da Histoire de Belgique apareceu em 1900, para ser exato; o sétimo e último volume em 1932. Trinta e dois anos de trabalho e quais trinta e dois anos! Essas lacerações mais íntimas foram adicionadas a ansiedades públicas às quais a amizade só podia ser mencionada com muita cautela. Regularmente, porém, volume após volume, o monumento não parou de se erguer, sem que nada pudesse comprometer a solidez de suas linhas ou alterar a sua serenidade". p. 273.

${ }^{13}$ Aqui me limito a citar o artigo Manuais ou sinteses? que apareceu em 1933 na revista Annales d'histoire économique et sociale, 1933, pp. 67-71. Para designar obras de histórias gerais e distinguir seu valor, ele usa os termos "manuais", "sínteses", "compêndios", mas coloca as obras mais importantes no "vasto campo da história geral": "Sobre esse período existem apenas livros especializados": quantas vezes, conosco, os nossos alunos ouviram essa frase, indesejada para os mais atormentados pela urgência! A partir de agora eles a ouvirão cada vez menos. Há alguns anos, as obras de síntese, ou aquelas que pretendem sê-lo, se acumulam nas prateleiras das nossas bibliotecas. Apontamos, há algum tempo, toda uma coleção de compêndios de história econômica aos quais outros, desde então, se adicionaram. Várias coleções paralelas - muitas delas em francês - evidentemente perseguem, no vasto campo da história "geral", uma nobre corrida de velocidade. Assim, ainda recentemente, quase ao mesmo tempo, pôde ser visto um novo volume da Cambridge Medieval History, cujo impulso apreciável não se deixa deter pelos
} 
pretendia realizar com seu magnífico primeiro trabalho, O Mediterrâneo e o Mundo Mediterrâneo na Época de Filipe II (traduzido no italiano como Civilizações e Impérios do Mediterrâneo na Era de Filipe II)? Ele queria fazer uma história geral, oferecer um quadro geral, o contexto geo-histórico no qual se encenam as atividades dos governantes e os eventos geopolíticos. O título já nos oferece todos os indícios para sustentar essa tese: civilizações e impérios são os personagens, os principais objetos da representação. No entanto, no prefácio escrito em 1946, o historiador é muito claro ao reivindicar a originalidade do caráter de sua "escala geral" dos fatos contra os livros que meramente representam a poeira de fatos sem importância.

Diversos estudos desse tipo [aqueles disponíveis sobre o Mediterrâneo] falam uma língua do passado, agora mais que um aspecto obsoleto. $\mathrm{O}$ que lhes interessa não é o vasto mar, mas esse ou aquele aspecto pequeno do seu mosaico; não a sua grande vida em movimento, mas as ações ou gestos dos príncipes e dos nobres, uma poeira de fatos sem importância e sem nenhuma conexão com a poderosa e lenta história que nos interessa. Diversos estudos desse tipo precisam ser retomados, trazidos de volta à escala geral dos fatos, elevados para restituir-lhes a vida. (BRAUDEL, 1953, p. XXXI).

A contraposição é proposta com grande clareza: por um lado, uma história clássica, isto é, tradicional e eventográfica (evenementielle); por outro, a história atenta aos grandes fatos da civilização, à vida fecunda e densa ${ }^{14}$.

Comecei o trabalho sob a forma clássica, certamente mais prudente, de um estudo dedicado à política mediterrânea de Filipe II. Meus professores na época o aprovaram muito. Eles enquadraram o trabalho nos padrões da história diplomática, bastante indiferente às conquistas da geografia, não muito solícita (como muitas vezes a própria diplomacia) com a economia e com os problemas sociais; bastante depreciativa em relação aos grandes fatos da civilização, às religiões e também às letras e às artes, às grandes testemunhas de toda história que tenha um valor e que, bem firme em seu partido tomado, proibia, a si mesma, de olhar além dos escritórios das chancelarias, na vida real, fecunda e densa. (BRAUDEL, 1953, p. XXXI)

E a designa como uma história geral:

Talvez um dia, nas oficinas historiográficas, não se trabalhe mais com nossos métodos de pequenos artesãos. Nesse dia, talvez, será lícito fazer história geral pesquisando textos originais, e não já, como agora, livros, mais ou menos, de primeira mão" (BRAUDEL, 1953, p. XXXII).

golpes do destino e, na coleção Peuples et civilizations, Louis Halphen, que é um de seus diretores, apresenta um importante Essor de l'Europe (XI-XIII siècles)". A tradução italiana se encontra na coleção de ensaios Storici e storia, p. 73.

${ }^{14}$ BRAUDEL, Fernand. Civiltà e imperi del Mediterraneo nell'età di Filippo II, Introdução, Torino: Einaudi, 1953. p. XXXI. 
Uma nova forma de história que acaba com as formas antigas:

Entender a história do Mediterrâneo na sua complexidade significa [...] lutar por uma nova forma de história, repensada, elaborada por nós e que merece atravessar as fronteiras; uma história imperialista, certamente, ciente de suas tarefas e suas possibilidades, também ansiosa, porque forçada a abandoná-las, a destruir as formas antigas com mais ou menos justiça, mas isso pouco importa! Não era, talvez, a ocasião propícia, apropriando-me de um personagem fora de série, para aproveitar sua grandeza, suas necessidades, suas resistências e suas armadilhas, e até mesmo seu ímpeto, para tentar construir a história de maneira diferente de como nossos mestres a ensinaram? (BRAUDEL, 1953, p. XXXII).

Uma história que tem o poder de interessar aos que não são historiadores e que pode lançar luz sobre o presente.

Porém, além desse drama, acredito que todos os problemas postos pelo Mediterrâneo sejam de uma riqueza humana excepcional e que, portanto, interessam tanto aos historiadores quanto aos não-historiadores. Penso também que esses problemas iluminam até o presente, que não sejam desprovidos daquela utilidade, no sentido mais estrito, que Nietzsche exigiu da história BRAUDEL, 1953, p. XXXII).

Sabemos que Braudel realizou outras histórias gerais: uma de tipo acadêmico, uma escolar, ambas de âmbito mundial; uma de divulgação sobre o Mediterrâneo na antiguidade, outras dedicadas à história da França. E colaborou com Labrousse na realização da História Econômica e Social da França. E sua obra e concepções inspiraram outras obras de história geral, como a de Immanuel Wallerstein.

Nas últimas décadas, surgiram obras de história geral altamente inovadoras, capazes de tornar conhecidos processos que afetaram toda a humanidade ou que são capazes de colocar os processos que se investiram e transformaram a Europa em conexão com o resto do mundo ou que dão as chaves para entender como chegamos à globalização.

\section{Para uma nova história geral escolar}

$\mathrm{O}$ que as novas histórias gerais elaboradas durante o século $\mathrm{XX}$ e o início do século XXI professam como alternativa à história geral herdada? Vamos analisar primeiro a estrutura da história geral considerada a única possível e digna de formar a cultura histórica básica dos súditos, outrora, e, hoje, dos cidadãos. De tal modo o historiador Yves Renouard ainda em 1950 a elogiava em uma apologia apresentada em um congresso mundial de historiadores. Renouard expressou com lucidez os argumentos que tornaram o paradigma do século XIX uma obrigação escolar: 
A história política expõe os principais acontecimentos do passado em relação à história militar e à história diplomática, enumerando regimes, reinos, ministérios, crises governamentais, grandes eventos; por último, ela apresenta os personagens. Ao fazê-lo, constitui - o que é frequentemente esquecido - o próprio quadro da história: colocando os acontecimentos em sua ordem cronológica, fixa os limites que servem para atribuir a todos os fatos não políticos a sua verdadeira sucessão e localização" (RENOUARD, 1968, p. 4142).

De acordo com os defensores e autores dessa história, quem são os sujeitos que fazem a história? São apenas os príncipes, os líderes religiosos, os protagonistas de algumas inovações e descobertas tecnológicas que influenciam o desenvolvimento dos fatos considerados relevantes. De acordo com essa visão distorcida, pessoas de origens não nobres nunca fazem história, muito menos mulheres.

Quais são os fatos considerados relevantes? Os fatos político-institucionais, diplomáticos e militares. As séries de eventos que mudaram os corpos estatais e a situação geopolítica. Como esses fatos são reconstruídos? São tratados como fatos singulares, envolvidos em uma cadeia que constitui a biografia da nação e as mudanças nas relações de poder no quadro europeu ocidental ou em escala planetária. Esses fatos são representados em seu breve desenvolvimento e são colocados em sequência de acordo com a data inicial de cada um. A historiografia eventográfica (evenementielle), que fragmenta os processos de transformação e justapõe, em ordem sucessiva, os segmentos factuais e cognoscitivos, distribuindo-os espacialmente e em várias partes do texto, mostrou-se completamente inadequada para produzir conhecimentos capazes de explicar a historicidade do mundo atual. A segmentação e a justaposição impedem o estabelecimento do sistema que garante que o conhecimento geral seja maior que a soma das partes.

São quatro as consequências dessa tematização e desse contexto:

I - A preferência por tematizações político-institucionais e militares leva à omissão de um grande número de fatos relevantes que poderiam dar conta das características do mundo atual. O leitor é, portanto, deixado na ignorância de fenômenos históricos que são decisivos para o destino da humanidade e do mundo.

II - O leitor se depara com conhecimentos que não têm relação com o presente, com as características do mundo atual, e que não as explicam, pois, a curto prazo, não produzem consequências duradouras. Elas precisam estar agregadas aos conhecimentos relativos a outros fatos. Mas os outros fatos, ou não são tratados (por exemplo, a continuação da revolução científica, a continuação da invenção do papel, da impressão 
tipográfica ou do regime feudal etc.), ou distanciam-se de seus precedentes por temas que dizem respeito a fatos estranhos ao processo de transformação iniciado. $\mathrm{O}$ efeito mais deletério é que a história estudada parece ser uma reconstrução sem sentido do passado, portanto, algo não interessante.

III - O leitor é levado a pensar que a história efetiva é uma questão de personagens poderosos ou particularmente inventivos e inovadores e que não é uma questão de sociedades, de coletividades, de pessoas comuns. Pelo contrário, os processos de grande transformação não poderiam ter sido realizados, com suas consequências duradouras até o presente, sem o protagonismo ou a participação ativa de massas de indivíduos.

IV - Assumindo que possa ser constituído, o conhecimento histórico básico não tem a possibilidade de constituir a estrutura, o pano de fundo adequado para estimular a aquisição de outros conhecimentos e a integrá-los dentro dessa estrutura.

Portanto, precisamos de outra história didática geral. Precisamos de uma história didática geral que torne imediatamente conscientes os alunos do fato de que eles mesmos estão dentro de histórias e contribuem para isso, enquanto se preparam para enriquecer as histórias que ocorrem nas comunidades locais, nacionais, europeias e mundiais. Portanto, devemos esclarecer a relação entre histórias feitas, efetivas, e a história como disciplina que as reconstrói e as representa metodicamente e com reflexão.

Precisamos de uma história didática geral que conscientize os alunos de que, entre as histórias feitas, estão os processos coletivos que geraram transformações e que gradualmente moldaram o mundo e a humanidade para conferi-la as características e os aspectos que os próprios processos coletivos ainda apresentam e para estimular as histórias que estão em desenvolvimento. Precisamos de uma história geral que inclua apenas, exclusivamente, os conhecimentos sobre fenômenos que podem ser conectados ao presente. $\mathrm{E}$ os textos deveriam começar precisamente destacando a dívida que o mundo atual possui com os processos que o geraram.

Devemos, portanto, aprender com os teóricos da nova história geral e com os novos trabalhos de história geral desenvolvidos durante os séculos XX e XXI para revolucionar o paradigma da história geral tradicional em três aspectos cruciais, a fim de responder aos desafios do mundo atual:

I - Construir um sistema de conhecimentos históricos diversos e organizados de acordo com periodizações mais adequadas à sua discussão; 
II - Aprender a relacionar as características, os aspectos, as histórias em curso no mundo atual com os presentes, as permanências e os processos que são tematizados pelos trabalhos de história; e

III - Aprender a comunicar os conhecimentos com descrições, narrações e argumentos que ensinam como refletir historicamente e com a redução dos nominalismos e abstrações incompreensíveis para jovens leitores.

O objetivo é formar a cultura histórica básica de todos os cidadãos, capaz de proporcionar chaves de leitura do mundo histórico atual e de promover o pensamento histórico. Aqui posso me limitar a propor apenas alguns exemplos de periodizações e tematizações alternativas.

Consideremos, por exemplo, um curso de história medieval e moderna que trata do nascimento do islamismo e da expansão árabe. Um tema e um conhecimento certamente relevantes. Mas a relevância e o significado disso são enfraquecidos por uma narrativa linear muito sucinta. No final, há informações superficiais e vagas sobre a civilização islâmica. Não é uma discussão que possa tornar os alunos capazes de relacionar o passado e o presente, de adquirir consciência dos traços e do patrimônio cultural deixados pela presença árabe e islâmica na Península Ibérica. Além disso, há uma falta de conhecimentos relevantes relacionados à expansão islâmica.

O que está faltando? Falta o conhecimento do relacionamento com o presente da Espanha e com o presente do mundo inteiro, como também do contexto mundial no início e no final do período. Acho intolerável que os estudantes não tenham a oportunidade de aprender sobre um processo de transformação formidável e decisivo para a história humana, como o que gerou a difusão da produção e dos usos do papel no mundo mediterrâneo e europeu a partir da Ásia. Estamos na era do papel há 2000 anos. A disseminação da produção e dos usos do papel graças aos chineses, árabes e italianos mudou a cultura e a civilização material.

Uma história feita por trabalhadores e mestres de obra da história, Droysen teria dito. A história do papel é um exemplo brilhante de contaminações interculturais. Está na origem de outro processo de grande transformação que é o da invenção e difusão da arte da impressão. Mas mesmo esse fato histórico tão crucial não é tratado. É apenas proposto como a invenção que permitiu a disseminação das ideias dos humanistas. Os atores dessas histórias eram artesãos modestos, trabalhadores, trabalhadoras e crianças, e valorizá-los a partir desse ponto de vista, respondendo à pergunta: "quem fez a 
história mais importante para a humanidade?", poderia gerar nos alunos uma reflexão sobre sua responsabilidade como agentes da história efetiva em andamento.

As histórias gerais que reconstroem a história da expansão islâmica, a do papel e a da imprensa nos ensinam como tratá-las, a fim de torná-las conhecimentos capazes de alimentar a inteligência do mundo histórico. Mas o modelo de história didática geral falha em abrir espaço para esses conhecimentos devido à hierarquia errônea dos elementos que têm relevância histórica.

Outro exemplo pode ser dado a propósito da unidade dedicada às grandes descobertas geográficas. O título, ou seja, a maneira de tematizar o processo de transformação, não permite que os alunos entendam sua importância decisiva para o devir do mundo e para a introdução da compreensão das características adquiridas após seu desenvolvimento. Aqui também, todas as referências ao mundo atual são omitidas, é ignorado o contexto global que foi transformado; a narrativa é banal e falsa devido à grande lacuna de informações. Mas a omissão mais séria é a de dois processos de grande transformação: a história da imprensa e a história das armas de fogo. Elas desempenharam um papel importante nos processos que chamamos de "expansão europeia", "globalização da economia" e "da história". E continuaram a exercer influência sobre o processo de formação do Estado centralizado e burocrático e sobre a história da reforma protestante e da transformação religiosa da Europa.

Além disso, em tais textos não há argumentos que possam ensinar os alunos a refletir. As reconstruções sem contextualizações e narrações do desenvolvimento são trivializadas como se o resultado fosse inevitável. Desse modo, elas se tornam algo de completamente extemporâneo ao saber historiográfico.

Então, como podemos pensar que essa história possa formar cidadãos ativos e democráticos? Eu poderia continuar com os exemplos. A história da ciência é reduzida à revolução científica e, depois de Galileu, Descartes e Newton, os alunos não aprendem mais nada, não sabem como a descoberta dos tempos geológicos da Terra e a formação da humanidade, que nos permitiu superar a versão bíblica, foram realizadas em dois séculos. Eles permanecem ignorantes também em relação às revoluções científicas do século XX. E o que dizer das omissões quanto à formação do Estado centralizado e burocrático, assim como do Estado de direito e do Estado democrático? E daquelas sobre o papel das mulheres nos processos históricos e sobre sua emancipação? E das omissões a respeito da criação das sociedades de massa? E quanto à alfabetização em que as mulheres desempenharam um papel crucial? A história do meio ambiente é 
totalmente ignorada, mas é crucial para entender como, no mundo, os ambientes foram transformados pelas histórias feitas por trabalhadores, mestres de obra, governos e como compreender e agir em relação aos riscos ambientais atuais.

\section{Considerações finais}

Em resumo, devemos aprender com Henri Berr a criar um catálogo de conhecimentos que possam constituir um cânone profundamente diferente daquele ainda hoje existente na história didática geral, que permita fundar uma cultura histórica, tornando os cidadãos capazes de saber que o mundo se transformou, daquilo que era há milhões de anos e tal como está agora, graças aos processos históricos. Além disso, essa nova cultura histórica possibilitará, por parte dos cidadãos, a compreensão de que o mundo, como produto de processos históricos, contém o passado. Precisamos de uma história didática geral que seja capaz de conscientizar os alunos de que eles também estão fazendo história e estão transformando o mundo e, portanto, têm a oportunidade de agir, neste mundo, com a cultura e o pensamento históricos.

Em dezembro 2004, Eric Hobsbawm publicou um Manifesto para a história no jornal Le Monde diplomatique traduzido para italiano no jornal Il Manifesto. , Nele sustentava ideias tais como:

A história está comprometida com um projeto intelectual coerente e progrediu na compreensão de como o mundo se tornou o que é hoje. [...] Uma história que considera o planeta em toda a sua complexidade, como uma unidade de estudos históricos, não como um contexto particular ou uma região circunscrita" (HOBSBAWM, 2004, p 4)

E no ensaio A história progrediu, ele já havia afirmado corretamente:

Porque, no final, a história se preocupa com como e por quê o homo sapiens passou da era do paleolítico para a era nuclear. [...] Se não abordarmos esse problema fundamental das transformações da humanidade, ou pelo menos se não considerarmos no contexto dessa transformação as atividades humanas que formam nosso campo especializado de pesquisa, nós, historiadores, nos reduzimos a falar sobre banalidades tolas ou nos envolvemos em algum jogo verbal ou intelectual. (HOBSBAWM, 1987, p. 81).

Hobsbawm não fazia uso do adjetivo geral, mas a história que ele pensava não podia ser realizada em uma monografia, já que era a "história" no sentido imaginado por Droysen, ou seja, uma história geral do mundo.

Para nós, que sabemos como a produção de histórias gerais progrediu durante o século XX, é necessário realizar a ideia de Hobsbawm em prol da disciplina escolar da 
"história" e do nosso bem-estar intelectual, assim como dos nossos alunos, para prepará-los a se tornar cidadãos do mundo.

\section{Referências}

BERR, Henri. Sul programma. In: ARCANGELI, Bianca e PLANTANIA, Margherita (orgs.). Metodo storico e scienze sociali. La Revue de Synthese Historique (1900 1930), Roma: Bulzoni editore, 1981.

BLOCH, Marc. Storici e storia. Torino: Einaudi, 1997.

BRAUDEL, Fernand. Civiltà e imperi del Mediterraneo nell'età di Filippo II. Torino: Einaudi, 1953.

- Il passato spiega il presente. In: Scritti sulla storia, Milano: Arnoldo Mondadori, 1973. $1^{\text {a }}$ ed. Encyclopédie française, vol. XX. Paris: Larousse, 1959.

DEMANDT, Alexander. Piccola storia del mondo, Roma: Donzelli, 2004.

DROYSEN, Johann Gustav. Istorica. Lezioni di enciclopedia e metodologia della storia (1857). In: CAIANIELLO, Silvia (org.), Napoli, Guida, 2003.

FEBVRE, Lucien, 'La part du directeur des "Cahiers"'/The editor's role', Cahiers d'Histoire Mondiale, n. 1, v. 1, 1953, p 198-201

FEBVRE, Lucien. Combats pour l'histoire. Paris: Librairie Armand Colin, 1965.

Civiltà: evoluzione d'un termine e d'un gruppo di idee. In Studi su Riforma e Rinascimento e altri scritti su problemi di metodo e geografia storica, Torino: Einaudi, 1966, p. 385-425.

- L'Europa. Storia di una civiltà. Edição francesa: Paris: Librairie Académique Perrin, 1999. Edição italiana: Roma: Donzelli editore, 1999.

GONZALEZ, Pilar Maestro. El modelo de las historias generales y la enseñanza de la historia; limites y alternativas. In Usos publicos de la historia. Universidad de Zaragoza, Ponencias del VI Congreso de la Association de Historia Contemporanea 2002. Prensa Universitaria de Zaragoza, Zaragoza 2003.

GOODY, Jack. Il furto della storia. Milano: Feltrinelli, 2008.

GUIZOT, François. Storia della civiltà in Europa. Torino: Einaudi, 1956.

HOBSBAWM, Eric. La storia è progredita? In De Historia. Saggi, Milano: Rizzoli, 1997.

Manifesto per la storia. Le Monde diplomatique/Il Manifesto, Paris-Roma, dezembro 2004. Disponível em: https://www.ildialogo.org/filosofia/manifestostoria05012005.ht. Acesso: 09 ago. 2020. 
ROMERO, Luis Alberto (org.). La Argentina en la escuela: La idea de nación en los textos escolares, Buenos Aires: Siglo XXI de España Editores, S.A., 2004.

LAFUENTE, Modesto. Historia General de España desde los tiempos primitivos hasta la muerte de Fernando VII. Por D. Juan Valera con la colaboración de D. Andrés Borrego y D. Antonio Pirala. Impresa en Barcelona por Montaner y Simón entre 1888 y 1890.

BERENGO, Marino. L'Europa delle città. Torino: Einaudi, 1999.

MACK SMITH, Denis. La storia manipolata. Bari: Laterza, 2002.

MATTOZZI, Ivo. Basta sapere la storia per insegnare bene?, Storia \& Futuro, 23, giugno 2010. Disponível em: www.storiaefuturo.com. Acesso em: 01 mar. 2017.

MARIANA, Juan. Historia general de España. Madrid: Gaspar y Roig, 1855.

TUTIAUX-GUILLON, Nicole. (org.). L'histoire scolaire au risque des sociétés en mutation.. Revista Raisons, comparaisons éducations. La revue française de l'éducation comparée, n. 4, 2009.

RENOUARD, Yves. Études d'histoire médiévale. Vol. I. Paris: SEVPEN, 1968.

VALLS, Rafael. Los manuales escolares españoles de Història. Revista d'Història de l'Educació, 3 (1997), p. 120-130.

Artigo recebido em 12 de agosto de 2020. Aprovado em 12 de outubro de 2020. 